Bol. Acad. peru. leng. 69. 2021 (93-124)

\title{
La configuración de la muerte en el discurso poético
} de Javier Heraud

The death's configuration in the poetic discourse of Javier Heraud

Le topique de la mort dans le discours poétique de Javier Heraud

\author{
Yoselin Quispe Mendivil \\ Universidad Nacional Mayor de San Marcos, Lima Perú \\ yoselin.quispe@unmsm.edu.pe \\ https://orcid.org/0000-0001-9973-9240
}

\section{Resumen:}

El presente artículo tiene como fin contrastar la configuración del tópico de la muerte en los poemas de Javier Heraud que pertenecen a la poesía pura, «Las moscas» $\mathrm{y}$ «Las cucarachas», frente a los que forman parte de la poesía social, «Balada del guerrillero que partió» y «Ellos». El estudio sostiene que, en los poemas de la poesía pura, se manifiesta una simbología bisémica representada mediante la figura del insecto, la cual alude al capitalismo y a la muerte; mientras que, en los poemas de la poesía social, se evidencia una simbología monosémica representada mediante la figura del río, que refiere a la vida.

Palabras clave: poesía social, poesía pura, Javier Heraud, símbolo monosémico y bisémico. 


\section{Abstract:}

The purpose of this paper is to contrast the configuration of the topic of death in the poems by Javier Heraud belonging to pure poetry, «Las moscas»[Flies] and «Las cucarachas» [Cockroaches], with those belonging to social poetry, «Balada del guerrillero que partió» [Ballad of the departed guerrilla fighter] and «Ellos»[They], respectively. The study argues that, in the poems of pure poetry, a bisemic symbology is represented by the figure of the «insect», which alludes to capitalism and death; while in the poems of social poetry, a monosemic symbology is represented by the figure of the «river», which refers to life.

Key words: social poetry, pure poetry, Javier Heraud, monosemic and bisemic symbol.

\section{Résumé:}

Le présent article a pour but de comparer la configuration du topique de la mort dans les poèmes de Javier Heraud appartenant à la poésie pure, «Las moscas» et «Las cucarachas», et dans ceux qui font partie de la poésie sociale, «Balada del guerrillero que partió» et «Ellos». Notre recherche soutient que, dans les poèmes de la poésie pure, il se manifeste une symbologie bisémique portée par la figure de «l'insecte», qui fait allusion au capitalisme et à la mort; tandis que dans les poèmes de la poésie sociale, on observe une symbologie monosémique représentée par la figure du «fleuve», qui renvoie à la vie.

Mots clés: poésie sociale, poésie pure, Javier Heraud, symbole monosémique et bisémique.

Recibido: 02/06/2020 Aceptado: 27/02/2021 Publicado: 30/06/2021 
https://doi.org/10.46744/bapl.202101.004

\section{Introducción}

El viaje a Cuba de Javier Heraud $(\mathrm{JH})$ marca un antes y un después en su producción poética. La primera etapa, según la crítica, se articula dentro de la poesía pura y se presenta antes de dicho viaje. La segunda etapa, para la crítica, se circunscribe dentro de la poesía social y se publica en vísperas de su viaje a Cuba. En esta segunda etapa, JH se hace llamar Rodrigo Machado, expresa sus convicciones políticas socialistas de forma descriptiva y sostiene que su discurso poético debe ser entendido por todos. El poeta tiene mayor interés en fusionar el fondo y la forma con el fin de dar conciencia social a sus lectores sin dejar de lado la estética de su obra. En este estudio se compara la configuración del tópico de la muerte en los poemas de JH que pertenecen a la poesía pura: «Las moscas» y «Las cucarachas» con los poemas que se circunscriben a la poesía social: «Balada del guerrillero que partió» y «Ellos». Con la investigación, se busca responder a las siguientes preguntas: ¿Cómo es el carácter simbólico en las dos etapas de la poesía heraudiana? ¿A qué se debe dicho carácter simbólico? ¿Cómo son las relaciones textuales en el discurso poético de Javier Heraud?

El presente artículo es importante porque reivindica el discurso poético del Poeta Joven del Perú, JH, y, en consecuencia, su perspectiva acerca de cómo debe configurarse el quehacer literario. Se tiene la hipótesis de que los poemas que pertenecen a la poesía pura contienen una simbología bisémica representada a través de las figuras de la mosca y la cucaracha que aluden a lo cotidiano, esto es, el capitalismo que en un inicio le es indiferente a la voz lírica. No obstante, con el tiempo, la presencia del capitalismo le causa molestia, por lo cual decide acabar con él, esto último es evidencia de la evolución del pensar del poeta. Luego, las figuras de los insectos se configuran como lo cotidiano que cobra relevancia con la muerte. Por otro lado, en los poemas pertenecientes a la poesía social, se evidencia una simbología monosémica representada mediante la figura del río, el cual se refiere a la 'vida'. Ambos poemas reflexionan en torno a los roles de las luchas revolucionarias y sus múltiples actores. 


\subsection{Poesía pura y poesía social}

Para JH, la poesía debe dejar de ser pura para convertirse en una poesía social. Según Damaso Alonso, citado por María Terol (2017), la poesía pura constituye la tendencia a eliminar lo personal, sentimental, patético, anecdótico, histórico del poema tachando en él lo que de un modo directo apela a las facultades humanas del hombre normal, que no es un intelectual ni un artista. De tal modo, se prioriza la estética del poema en desmedro de las temáticas sociales.

Por otra parte, Luis Fernando Chueca (2020) señala que el discurso poético de JH constituye «una poesía articulada a las necesidades comunicativas del poema y a su radicalización política en curso» (p. 30). En la entrevista realizada por Mario Vargas Llosa a JH en París de 1961, este último sostiene que busca configurar una poesía social, esto es, una poesía que «lejos de ser una solitaria y aislada creación del artista, es testimonio de la grandeza y la miseria de los hombres, una voz que denuncia el horror y clama la solidaridad y la justicia; y la felicidad, algo inalcanzable fuera del destino común que debe ser conquistado».

\subsection{La poesía social de Rodrigo Machado}

La hermana de Javier Heraud, Cecilia, citada por Carlos Villacorta (2014), afirma que Rodrigo Machado, seudónimo del poeta Javier Heraud, hace alusión a dos personajes literarios: Rodrigo Díaz de Vivar, el Cid, y el poeta español Antonio Machado. Carlos Villacorta (2014) considera que estos personajes literarios simbolizan los rasgos contestatarios y la aptitud para la poesía de Heraud. Para Machado, citado por Villacorta (2014), la poesía puede enriquecerse de artes como el cine, la música, entre otras, pero sin perder claridad; asimismo, es necesario que el lenguaje de la poesía sea inteligible para todos los estratos sociales. Así, dicha claridad del lenguaje será el rasgo predominante del estilo de Rodrigo Machado. 
https://doi.org/10.46744/bapl.202101.004

\section{Marco teórico}

\subsection{Símbolo monosémico y símbolo bisémico}

Para Bousoño, citado por Cornejo Polar (1966), el símbolo monosémico constituye «la atribución de cualidades irreales a un objeto» (p. 344). En la poesía de $\mathrm{JH}$, los rasgos del río representan al poeta. Esto se evidencia, sobre todo, en el poema «El río». Sin embargo, Cornejo Polar sostiene que la dualidad poeta-río alude a la creación artística, la humanidad, el cosmos y la vida. Asimismo, Cornejo Polar (1966) señala que el símbolo bisémico constituye un doble juego significacional, pues, por un lado, los versos del poema en cuestión le atribuyen al referente sus características propias y, por otro lado, los mismos versos aluden al referente «como algo mucho más grande, trascendente y actuante» (p. 342).

\subsection{Partes orationis del discurso según el modelo de Perelman}

Según Perelman (1997), en un discurso formal, el orden de las partes del discurso carece de importancia, pues se trata de expresar a los postulados el valor de veracidad en relación con las hipótesis del argumento. No obstante, cuando la finalidad del discurso es argumentar para persuadir al auditorio, el orden es importante.

Perelman (1997) señala que el orden de los argumentos en el discurso se constituye de la siguiente forma:

a) Exordio: Tiene la finalidad de incitar la benevolencia y el interés del público con respecto al discurso del orador.

b) Narratio: Constituye la exposición de los hechos del discurso.

c) Argumentatio: Puede seguir o preceder la tesis del discurso. Si el argumento pretende convencer al auditorio, puede enunciarse después que la tesis, pero si el argumento tiene el propósito de conmover al público, se sugiere que dicho argumento se enuncie primero que la tesis. 
d) Peroratio: Constituye la síntesis de todo lo expuesto en el discurso, así como la captación de la benevolencia del público.

\section{Metodología}

Para analizar la configuración del tópico de la muerte, se escogieron los siguientes cuatro poemas de Javier Heraud: «Las moscas», «Las cucarachas», «Balada del guerrillero que partió» y «Ellos» porque en estos se presenta el foco de estudio de forma marcada. Estos poemas pertenecen al libro Javier Heraud/Poesías completas (1975), el cual se encuentra disponible en las Biblioteca Central Pedro Zulen de la Universidad Nacional Mayor de San Marcos. Asimismo, para realizar el estudio, se decidió utilizar los marcos teóricos de la Retórica y la Literatura Comparada propuestos por Arduini (2000) y Steiner (1978-1992), respectivamente, ya que el objetivo de este trabajo es contrastar los poemas de Javier Heraud pertenecientes a la poesía pura con los poemas circunscritos a la poesía social, esto es, los poemas de Rodrigo Machado. El trabajo de investigación tiene como fin determinar la cosmovisión del sujeto poético, a partir de la señalización de las figuras retóricas, las cuales permiten constatar y sustentar las diversas interpretaciones que se le podría dar a un poema.

\section{Análisis e interpretación}

En esta sección, se interpretarán cuatro poemas de distintas épocas para luego compararlas y así poder identificar los cambios y continuidades dentro de la producción heraudiana.

\subsection{Análisis de «Las moscas», de Javier Heraud}

«Las moscas» es un poema cuasidialógico en el sentido de que se forma a partir del monólogo que le dirige el locutor al alocutario. En ese sentido, a través de las estrategias del comentario, la aclaración, la advertencia y la petición, el locutor del poema esgrime una situación cotidiana que se evidencia a partir de la interacción entre humano y animal, persona e insecto. El análisis formal desde la perspectiva de la Retórica servirá como base para sostener la hipótesis planteada anteriormente. 
https://doi.org/10.46744/bapl.202101.004

\section{Las moscas}

Claro, señorita mosca,

Ud. vuela graciosamente

Ud. se dibuja con su sombra

movediza en las paredes,

Ud. parece reírse de mí,

porque yo ni la miro

débilmente,

y Ud. se posa en mi nariz,

se para en mi cabeza,

se posa sobre mi hombro

y hasta diría le gusta,

ay señorita mosca,

que yo le ponga

inútilmente mi mano

para matarla,

pues Ud. se ahuyenta,

levanta el vuelo,

y se posa sobre mi pan,

mis tostadas, mis libros

que aguardan su llegada.

iAy! Señorita mosca,

me dicen que Ud. puede

traer males terribles

pero yo no les creo,

$\mathrm{y}$ a donde suelo ir

la encuentro

nuevamente,

molestando con sus

alas.

Y claro

solo los tontos

compran rejilla con mango,

o un periódico viejo,

y la persiguen 
hasta que la ven caer, moribunda.

Es oficio de ociosos, eso de matar moscas diariamente, pues Ud., señorita mosca, no asusta ni a las vacas ni a los perros.

Pero le advierto:

si algún día yo pudiera, reuniría a todos los sabios

del mundo, y les mandaría fabricar un aparato volador que acabaría con Ud. y sus amigas para siempre.

Solo espero no alimentarla y no verla en mis entrañas, el día que si acaso me matan en el campo y dejan mi cuerpo bajo el sol.

\subsubsection{Dispositio o segmentación del poema}

En el nivel de la dispositio, la segmentación del poema «Las moscas» considera la temática de los versos y está dividida en cuatro segmentos. El primero constituye desde el verso 1 al verso 20 (lo cotidiano busca captar la atención de la voz lírica). El segundo segmento va desde el verso 21 al verso 42 (la incredulidad del poeta de que lo cotidiano pueda causar catástrofes). El tercer segmento corresponde desde el verso 43 al verso 50 (el deseo del poeta de acabar con lo cotidiano). Por último, el cuarto segmento va desde el verso 51 al verso 55 (la intervención de lo cotidiano en el momento de la muerte). 
https://doi.org/10.46744/bapl.202101.004

\subsubsection{Elocutio o los campos figurativos}

Es importante la señalización de las figuras retóricas inscritas en el poema, ya que constituyen la articulación del pensamiento poético; esto es, la visión del mundo del poeta. No se trata de un mero cotejo de figuras, sino de la articulación de una tesis expresada en la forma literaria. Las figuras retóricas permiten constatar y sustentar las diversas interpretaciones que se le podría dar a un poema. Fundamentan, en sentido estricto, la orientación que un lector le da al poema. En tal sentido, se puede señalar que el campo figurativo más resaltante a lo largo del poema es la metáfora. Así, en el primer segmento, se evidencia la figura de la personificación en los versos «Ud. se dibuja en el aire, se dibuja con su sombra movediza en las paredes» y «Ud. parece reírse de mí, porque yo ni la miro débilmente» (v. 3-8), donde la mosca adquiere características humanas. En este segmento, se presenta la figura retórica de la antonomasia, cuando el locutor se refiere a la mosca cortésmente con el nombre de señorita mosca. El adjetivo señorita alude a un hecho que tiene influencia reciente en la sensibilidad del yo poético. Volveremos, luego, con la metáfora. Asimismo, a lo largo del poema se destaca el campo figurativo de la repetición del pronombre $U d$., el cual también expresa la humanización de la mosca. La mosca remite a lo cotidiano, a lo rutinario que llama la atención del orador del discurso. El pronombre, además, indica cierto aire de respeto y distancia comunicativa. La segunda persona, en el español, tiene dos variantes, el tú que marca cierto acercamiento y confianza, y el $U d$. que desplaza la comunicación hacia un aura solemne y seria. El pensar repetitivo se mantiene a lo largo del fragmento (se advierte también la aparición de asíndenton) en cuanto la mira del locutor se dirige a nombrar referentes de la cotidianidad: pan, tostadas y libros.

En el segundo y tercer fragmento, se presenta el campo figurativo de la antítesis, cuando el locutor se refiere a los tontos y a los sabios. Según la presente tesis, el locutor explicita esta oposición para expresar que un cambio social se logra de forma organizada. Ello va ligado, nuevamente, al campo figurativo de la metáfora que aparece de forma insistente en esta sección. En los versos «Y claro solo los tontos compran rejilla con mango, o un periódico viejo, y la persiguen hasta que la ven 
caer, moribunda» (v. 30-37) y «Pero le advierto: si algún día yo pudiera, reuniría a todos los sabios del mundo, y les mandaría fabricar un aparato volador que acabaría con Ud. y sus amigas para siempre» (v. 44-51), el locutor enuncia que el uso de herramientas de la cotidianidad (la rejilla con mango o el periódico) para matar moscas diariamente es un oficio de tontos y ociosos. Estas herramientas constituyen metáforas, las cuales aluden a que una revolución con armas artesanales y sin la debida organización sería una pérdida de tiempo. Por otro lado, el aparato volador constituye una metáfora, la cual se refiere a que una lucha organizada con un instrumento más elaborado y radical como las armas de fuego es la única vía para lograr un gran cambio social. A partir de lo expuesto, se llega a la conclusión de que la mosca constituye una metáfora que se refiere al capitalismo. En el poema, el capitalismo o la mosca representan lo cotidiano que en un inicio le es indiferente a la voz lírica. No obstante, con el tiempo, la presencia del capitalismo le causa molestia, por lo cual decide acabar con él, esto último es evidencia de la evolución del pensar del poeta.

En el cuarto segmento, se evidencia que la mosca constituye lo cotidiano que cobra relevancia con la muerte. Así, la mosca representa la insistencia de una figura minúscula pero molesta, que incluso en la muerte estará ahí, ya no solo posando su cuerpecito sino devorando el inmenso cuerpo del locutor. A partir de lo expuesto, se concluye que la mosca constituye un símbolo bisémico, ya que primero alude al capitalismo (lo cotidiano) y luego representa un símbolo de la muerte.

\subsubsection{Interlectio o los interlocutores}

En el poema «Las moscas», el locutor personaje se dirige a un alocutario representado; esto se evidencian a partir de la marca del pronombre $U d$., el cual implica a la primera persona. Esta relación que ha sido denominada cuasidialógica, pues en ningún momento hay respuesta de la señorita mosca, apela a la reflexión del locutor respecto a un insecto que le causa molestia debido a la provocación generada por su minúscula presencia, ya que adónde va el locutor encuentra a la mosca «molestando con sus alas». Así, en el primer segmento, le 
https://doi.org/10.46744/bapl.202101.004

dirige un comentario sobre sus actividades molestas; luego, le aclara su posición insignificante en relación con las actividades del mundo; después, le advierte sobre la intención de desaparecerla junto a sus amigas $\mathrm{y}$, por último, le indica el deseo de no verla cuando ya esté muerto. Con esta escala discursiva que dirige el locutor a la mosca, se busca expresar las valoraciones negativas de la continuidad del capitalismo en la sociedad.

\subsubsection{Inventio o la visión del mundo}

En el poema, la presencia de la mosca se torna insistente a través de la recurrencia de su mención mediante el pronombre $U d$. y su apelativo de señorita. Así, el campo figurativo de la repetición se condice con la molestia generada y que se expresa textualmente desde el verso 25 hasta el 30. La mosca, por ende, es un objeto que copa la atención plena del locutor. La descreencia prima en los primeros versos, para luego convertirse en moralización y, finalmente, en deseo de separación. La provocación inicial genera un desconcierto que torna repetitiva y rutinaria la existencia del sujeto poético. La mosca desafía la presencia del locutor cuando se posa en su cuerpo, sus alimentos y sus libros. Los objetos que la circundan «esperan su llegada», lo que manifiesta esta interacción repetitiva al punto que la personificación identificada en la mosca se extiende a lo que rodea al locutor. Como se dijo, estos eventos, a pesar del fastidio que generan, no son tomados en serio. Al contrario, se desmiente la creencia, el conocimiento cotidiano, pues «me dicen que Ud. puede / traer males terribles, / pero yo no les creo». Hay acá una oposición interesante: la cotidianidad de las moscas, que influyen en la subjetividad del locutor, no son tomadas tan en cuenta, sino que solo son presencias insistentes, pero que no pasan de una leve molestia.

Ahora bien, estos elementos se relacionan con tres figuras más que interesantes, figuras metafóricas que aluden a rasgos puntuales: los tontos, los ociosos y los sabios. Los primeros se destacan por la limitación de su cognición: un tonto tiene por rasgo ser lento y torpe en cuanto a sus decisiones. En este caso, el locutor relaciona a los tontos con dos instrumentos: una rejilla con mango o un periódico viejo. El 
primero es un elemento más que cotidiano, un matamoscas; el segundo es más esclarecedor, dado que el medio informativo se transforma en objeto de tontos, pues su función principal es dejada de lado para convertirse en arma bruta. Los segundos, los ociosos, se califican por su poca movilidad o energía reducida al momento de realizar una acción. En este caso estamos en una escueta contradicción, porque, aunque los ociosos no hacen mucho por la naturaleza, en este poema matan moscas diariamente. Pero su acción es insignificante, pues, al decir del locutor, las moscas no provocan miedo, sino solo una leve molestia. Los terceros, los sabios, constituyen un grupo más complejo. Su misma nominación contradice su naturaleza, ya que estos van a fabricar un aparato para acabar con las moscas; con lo insignificante, su labor se ve reducida a lo mínimo, desacralizada por el momento en que viven, de pequeñas moscas molestosas.

Estos valores invertidos, figurados con densas metáforas, constituyen el núcleo problemático del poema. El capitalismo se incorpora en la vida de las personas en proporciones minúsculas, pero que generan grandes cambios en todos los niveles de acción. Los objetos pierden su funcionalidad (los periódicos); los trabajos se realizan, pero a merced de no valer la pena (los ociosos); y el pensamiento se reduce a su manifestación técnica (los sabios). En ese sentido, el capitalismo genera molestia en los ámbitos de la vida del locutor: el insecto volador se posa en pan, galletas y libros, alimentación y conocimiento se ven invadidos por estos pequeños seres, además de incidir en el cuerpo del locutor.

Además, la mosca señala también el final del locutor: su muerte. La mosca se asocia al estado mortuorio cuando se posa en el cadáver descompuesto. Ahora bien, la perspectiva acota que la muerte está asociada a la presencia de las moscas, debido a que estas se alimentan del cadáver; sin embargo, esto es lo que se desea evitar: si el capitalismo ya se introdujo en todos los ámbitos de la existencia humana, solo le queda al locutor una vida en constante frustración por la presencia de las moscas-capitalismo. El anhelo del locutor es librarse de las moscas en su muerte para lograr emanciparse del capitalismo. 


\subsection{Análisis de «Balada del guerrillero que partió», de Javier Heraud}

La perspectiva de este poema es distinta al anterior en la medida en que estamos ante la proyección de una fábula heroica y melodramática presentada por un locutor no personaje. Si bien es un poema, el tono narrativo es imperante para su compresión, pues difiere de la perspectiva coloquial del poema anterior, «Las moscas». Seguiremos el mismo procedimiento para identificar las figuras pertinentes y su significación principal.

\section{Balada del guerrillero que partió}

Una tarde díjole a su amada:

«Me voy, ya es tiempo de lluvias, todo está anegado

la vida se me envuelve en la garganta

no puedo resistir más opresión.

Mientras mis hermanos

mueren en las sierras por balas

asesinas,

yo no debo quedar pensativo,

indiferente.

Adiós, me voy a los montes

con los guerrilleros».

Se despidió y partió.

Y un día ya estaba arriba, de brazo con los guerrilleros.

Fue su mano espada de plata fina,

aró, sembró y cosechó

la tierra,

disparó con su fusil rayos

de esperanza,

y otro día ya estaba muerto,

con dos metro de tierra

sobre el hombro.

Pensativo y triste

aún recuerda a su amada 
inmemorial por largo tiempo.

Y ella lo espera junto al río, en el puente en donde lo vio partir.

$\mathrm{Y}$ acaricia su vientre con tristeza, pensando en él, en todos, con sus ojos hermosos

y radiantes

mira hacia el puente, al río,

a la vida.

Y siente en su corazón

la esperanza, la nueva

alegría que su amado juntó

en la tierra.

\subsubsection{Dispositio o segmentación del poema}

En el nivel de la dispositio, la segmentación del poema «Balada del guerrillero que partió» considera tres segmentos según el criterio temático. El primer segmento constituye desde el verso 1 al verso 13 (el guerrillero se despide de su amada). El segundo segmento va desde el verso 14 al verso 23 (el guerrillero muere en el campo de batalla). Finalmente, el tercer segmento corresponde desde el verso 24 al verso 38 (la amada del guerrillero recuerda con esperanza a su amado).

\subsubsection{Elocutio o los campos figurativos}

Con respecto a la señalización de las figuras retóricas inscritas en el poema, las cuales configuran el pensar y la visión de mundo de la voz lírica, se puede afirmar que el campo figurativo más resaltante a lo largo del poema es la metáfora. En el primer segmento, en el verso «la vida se me envuelve en la garganta» (v. 4), se evidencia el campo figurativo de la personificación, cuando la voz poética alude a que el guerrillero ya no puede estar más tiempo sin enunciar su voz de protesta. Asimismo, en el segundo segmento, en el verso «Fue su mano espada de plata fina» (v. 16), se puede visualizar una metáfora que se refiere a que el guerrillero peleó en el campo de batalla con el fin de promover su pensamiento político socialista. En los versos «disparó 
https://doi.org/10.46744/bapl.202101.004

con su fusil rayos de esperanza» (v. 19-20), se evidencia una metáfora que hace referencia a que la lucha armada en contra de los representantes del capitalismo producirá un futuro prometedor en la sociedad. Además, en los versos «y otro día ya estaba muerto, con dos metros de tierra sobre el hombro» (v. 21-23) se presenta el campo figurativo de la sinécdoque; esto es, la parte por el todo, que alude a que el guerrillero murió por sus convicciones políticas socialistas. En los versos se señala la parte (el hombro) para referirse al todo (el guerrillero). El tercer segmento, en los versos «Pensativo y triste aún recuerda a su amada inmemorial por largo tiempo» (v. 24-26) se evidencia la figura de la hipérbole, la cual se incluye dentro del campo de la antítesis, que se refiere a que cuando el guerrillero se encontró en el campo de batalla, sintió añoranza de su amada por estar largo tiempo lejos de su presencia. Finalmente, en los versos «Y acaricia su vientre con tristeza pensando en él, en todos, con sus ojos hermosos y radiantes mira hacia el puente, al río y a la vida» (v. 29-34), se puede observar, nuevamente, una metáfora que hace alusión a que, a pesar de que el guerrillero murió en el campo de batalla, su pensamiento político se prolongará en la tierra mediante la figura de su hijo, quien continuará con la misión de acabar con el sistema capitalista. En tal sentido, el río y el vientre de la amada del guerrillero simbolizan la vida, la esperanza de un futuro prometedor que solo será posible a través de la configuración de una sociedad organizada mediante el pensamiento socialista. Así, a través del campo figurativo de la metonimia de causa-efecto se llega a la conclusión de que la partida del guerrillero simboliza su muerte física y al mismo tiempo representa la esperanza de la llegada de una sociedad de perspectiva socialista más justa para todos, que encarnará su continuación en el vástago por venir.

\subsubsection{Interlectio o los interlocutores}

En «Balada del guerrillero que partió», el locutor es no personaje y el alocutario es no representado, pues el poema está escrito en tercera persona. Así, la perspectiva se instala en un ambiente narrativo y solemne. La balada es un dispositivo poético de larga data. Su estatus se destaca por el carácter ritual que implica. En el texto de Heraud, se observa la intención de provocar un distanciamiento celebratorio y serio del suceso a partir 
de la escenificación de la vida del guerrillero, para representarlo como ejemplo de héroe, y así mover la conciencia del alocutario. En este caso, su no representación en el poema abre la posibilidad de que la balada amplíe su radio de difusión, pues no va dirigida a un sujeto concreto, sino a uno impersonal.

\subsubsection{Inventio o la visión del mundo}

El poema parte de la premisa de una situación anclada temporalmente. Se habla de un guerrillero que partió. El título es esencial en la configuración del sentido, ya que alude a la decisión del personaje principal del poema. Este no es obligado, tampoco seducido, sino que por determinación propia decide partir, salir a buscar lo que anhela. ¿Pero qué es? El título juega retóricamente con el suspenso, este obliga a ir al cuerpo del poema para enterarnos de lo que pasará. La estrategia está bien calibrada, dado que incentiva el deseo de investigar mediante la acción misma lo que puede suceder si nos atrevemos a averiguar lo que viene después.

Los primeros versos aluden a la explicación del guerrillero de partir para acompañar en las luchas que se desarrollan en las sierras. El personaje principal siente que no puede estar viviendo aislado, indiferente, ante lo que acontece: la muerte de hermanos por balas asesinas, metonimia de los enemigos, los soldados, el Estado, el capitalismo. Así, se opone el pensamiento a la acción en el verso nueve. Su estado de reflexión es óbice para cumplir con su deber, combatir a lado de sus hermanos. La metáfora más resaltante es la de su mano que fue espada de plata fina. Esta realizó acciones importantes: arar, sembrar y cosechar, pero también disparar, aunque no solo balas, sino «rayos / de esperanza». Pero estas acciones ejemplares, dignas de comentario y reflexión, chocan con la muerte repentina del guerrillero: "Y un día estaba... / y otro día ya estaba muerto». Se enfatiza la mortalidad de los hombres que van a combatir. No se muestra una imagen idealizada. Al contrario, estos sujetos aman, trabajan, pelean, y, efectivamente, también mueren.

La figura sinecdóquica de la tierra sobre el hombre tiene doble significación: en principio, alude a la tierra que se coloca encima del 
https://doi.org/10.46744/bapl.202101.004

cadáver al ser sepultado, pero también alude a lo que una persona carga sobre sí, el peso que lleva en los hombros, su trabajo, su esfuerzo, su vida, síntesis. En ese sentido, la muerte de un guerrillero implica una serie de circunstancias que pesaban sobre él. De ahí que el pensamiento último es hacia su amada. La lucha se sostiene o se acompaña en el amor, en la relación íntima con la pareja; y la angustia («Pensativo y triste») recae en la responsabilidad de dejarla sola. La hipérbole enfatiza ese carácter sagrado de la relación amorosa eterna, la fidelidad en el doble frente: el personal y el comunal.

Finalmente, la muerte del guerrillero no significa fin, sino breve pausa, breve interrupción del proceso revolucionario. La visión que el locutor continúa respecto de la amada del guerrillero es importante, pues va escalando emotivamente: "mira hacia el puente, al río, / a la vida». Este proceso es un aumento de la perspectiva de la amada, quien logra comprender la magnitud del sacrificio. La muerte, finalmente, se torna vida, esperanza, en el vientre fecundado. El puente es un pasaje; el río, un tránsito; la vida, la continuidad de la lucha, de la existencia. Los versos finales apuntan en ese sentido: «la nueva / alegría que su amado juntó / en la tierra». Y en este juego metafórico se conectan, subrepticiamente, cuerpo y tierra. La fecundación es doble: el guerrillero ha fecundado doblemente. La tristeza se torna alegría, porque el amado no ha partido, ha reencarnado en su descendiente para continuar sus luchas, sus esperanzas, sus sueños, sus trabajos en busca de eliminar la opresión.

\subsubsection{Análisis comparativo de «Las moscas» frente a «Balada del guerrillero que partió»}

En el poema «Las moscas», el locutor está personificado y el alocutario está representado, mientras que en el poema «Balada del guerrillero que partió», el locutor no está personificado y el alocutario no está representado. En «Las moscas» se expresa el pensamiento socialista emergente de la voz lírica a través de una gran profusión de figuras literarias, de las cuales predominan los campos figurativos de la repetición y la metáfora. Por otro lado, en «Balada del guerrillero que partió», el campo figurativo más resaltante 
es la metonimia de causa-efecto. La partida del guerrillero representa su muerte física en el campo de batalla; sin embargo, de forma simultánea representa la esperanza de un futuro prometedor que solo será posible mediante la configuración de una sociedad organizada por el pensamiento socialista y ejemplificada en la nueva vida que está en camino. En este poema, se tiene como fin que el poema sea comprendido por todos y es por ello que en él se evidencia un lenguaje más claro.

En el poema «Las moscas», el insecto constituye un símbolo bisémico. En primera instancia, la mosca representa lo cotidiano que cobra relevancia con la muerte. Lo cotidiano es entendido como la consecuencia del sistema capitalista. Luego, la mosca simboliza el fastidio de que lo aceche aún en su muerte, en el campo de batalla; es decir, representa un símbolo de la muerte. Por otro lado, en el poema «Balada del guerrillero que partió», se presenta al río como un símbolo monosémico, pues solo simboliza la esperanza de la amada del guerrillero y de los continuadores del pensamiento socialista, que luchan por la configuración de una sociedad más justa para todos, en la imagen del vientre fecundado.

En el primer poema, el tono es coloquial y simbólico. La mosca tiene distintos planos de significación, tanto en su representación cotidiana, como en su figuración mortuoria. Esto crea una tensión entre la forma dialógica, coloquial, y el contenido profundo y reflexivo. En cambio, en el siguiente poema, se nota la solemnidad del lenguaje y el uso de expresiones más destellantes, como «las manos de plata» o «los ojos radiantes». Esto igualmente tensiona los dos planos del poema al mostrar mediante una balada, artefacto altamente poético, una anécdota narrativa.

\subsection{Análisis de «las cucarachas», de Javier Heraud}

$\mathrm{Al}$ igual que «Las moscas», «Las cucarachas» es un poema cuasidialógico en el sentido de que se forma a partir del monólogo que le dirige el locutor al alocutario, que en este caso cambia de insecto. En «Las cucarachas», por otra parte, se opta por la sinceridad, la aclaración, la advertencia y la develación. 


\section{Las cucarachas}

Señora cucaracha:

en verdad, no la amo ni un poquito, pero me da pena matarla

diariamente.

Sí, claro,

tal vez comprendo

que su venida a mi cuarto

no responde a motivos especiales:

pero me apena

ensuciar mi zapato

de ese lechoso líquido

que Ud. deja en el suelo cuando la piso

y siempre el mismo chirrido,

y Ud. quiere escaparse,

y yo que fácilmente

le pongo mi zapato

sobre su fina piel, sobre su cuerpo entero, sobre sus patas curvándose

impotentemente sobre la madera.

$\mathrm{Y}$, ya ve Ud.,

no acostumbro matar

cucarachas,

mis padres nunca

me dijeron:

«has de matar todas

las del mundo,

con esta espada y etc., etc.»,

pero es que además

me molesta su maldita

indiscreción

cuando se mezcla

con mi ropa,

cuando se esconde 
en mi maleta cada

vez que viajo,

cuando la encuentro

reposando encima

de mi almohada.

Yo quisiera prevenirla,

avisarle,

decirle que nunca más

pase por aquí,

que aquí,

debajo de este arco

pequeño de mi puerta

encontrará definitivamente

todas las noches, la muerte,

y que aunque dios,

o los ángeles la protejan.

siempre dejará su

leche blanquecina,

sus entrañas pequeñitas,

sus patas dramáticamente

rasgando el cielo,

e irá a dar,

como todos los días,

al fondo de la basura

y de la nada.

\subsubsection{Dispositio o segmentación del poema}

El texto lírico «Las cucarachas» consta de 59 versos, los cuales están divididos en cuatro segmentos según el criterio temático. El primer segmento va del verso 1 al 4 (el poeta enuncia la pena que siente de acabar con lo cotidiano); el segundo, de la línea melódica 5 a la 20 (el poeta explica los motivos de la pena que siente de acabar con lo cotidiano); el tercero, desde el verso 21 al 39 (el poeta señala los motivos de su molestia por la presencia de lo cotidiano); y el último, de los versículos 40 al 59 (el poeta desea prevenir a lo rutinario del peligro en que se encontrará si se acerca demasiado). 
https://doi.org/10.46744/bapl.202101.004

\subsubsection{Elocutio o los campos figurativos}

En el primer segmento, se presenta la figura retórica de la antonomasia, cuando el locutor se refiere a la cucaracha cortésmente con el nombre de señora cucaracha. El adjetivo señora alude a un hecho trascendente que tiene considerable influencia en la sensibilidad del yo poético. Desde el segundo segmento hasta el final del poema, se destaca el campo figurativo de la repetición del pronombre $U d$., el cual expresa la humanización de la cucaracha. La cucaracha remite a lo cotidiano, a lo rutinario que llama la atención del locutor del discurso. El pensar repetitivo se mantiene a lo largo del segundo segmento (se advierte también la aparición de la anáfora y el polisíndeton) en cuanto la mira del locutor se dirige a nombrar referentes del cuerpo de la cucaracha en los siguientes versos: «y siempre el mismo chirrido, $y \mathrm{Ud}$. quiere escaparse, y yo que fácilmente le pongo mi zapato sobre su fina piel, sobre su cuerpo entero, sobre sus patas curvándose impotentemente sobre la madera» (v. 13-20; nuestras cursivas). La preposición alude a la ubicación jerárquica entre las dos presencias del poema.

En el tercer segmento, el locutor se dirige al alocutario representado, la cucaracha, para señalarle lo siguiente: «Y ya ve Ud. / no acostumbro matar / cucarachas, / mis padres nunca / dijeron: / «has de matar todas / las del mundo, / con esta espada y etc, etc»» (v. 21-28). En estos versos, se indica que los padres de la voz lírica no le inculcaron el uso de armas para acabar con las cucarachas. Así, a la cucaracha se le atribuyen los rasgos de peligrosa y dañina y, por ello, merece ser exterminada. En este segmento, es preponderante el campo figurativo de la repetición del determinante posesivo mí, cuando el locutor señala que la cucaracha invade su privacidad. La repetición se evidencia en los siguientes versos: «pero es que además / me molesta su maldita / indiscreción / cuando se mezcla / con mi ropa, / cuando se esconde / en mi maleta cada / vez que viajo, / cuando la encuentro / reposando encima de mi almohada» (v. 29-39; nuestras cursivas). Así, se concluye que la cucaracha constituye una metáfora del capitalismo. La cucaracha o el capitalismo representan una amenaza al espacio personal de la voz lírica. 
En el cuarto segmento, se reafirma que la cucaracha constituye una metáfora del capitalismo, cuando el locutor señala lo siguiente: «y aunque dios / o los ángeles la protejan, / siempre dejará su / leche blanquecina, / sus entrañas pequeñitas, / sus patas dramáticamente / rasgando el cielo, / e irá a dar, / como todos los días, / al fondo de la basura / y de la nada» (v. 49-59). Según la voz lírica, el capitalismo está resguardado por la Iglesia Católica, pero su continuidad no es viable en la sociedad en la que vive y, por ello, luchará para lograr su muerte o exterminio. En este sentido, la crítica a la modernidad no se da solo a sus valores, sino también a su idea de tiempo. Así, se deduce que la cucaracha constituye un símbolo bisémico que, en primera instancia, representa a la cotidianidad (el capitalismo) y, en segundo lugar, constituye un símbolo de la muerte.

\subsubsection{Interlectio o los interlocutores}

En el poema «Las cucarachas», el locutor personificado se dirige a un alocutario representado, la cucaracha, que metaforiza la cotidianidad; esto es, se busca la configuración de la muerte por medio del insecto. Sin embargo, mientras en las moscas, el insecto actualizaba la muerte, como fenómeno inherente al locutor, en este poema, el animal se relaciona en su naturaleza con la defunción, pues lo que se busca es que este desaparezca con todas sus implicancias negativas. Así, a lo largo del poema, se evidencia la individualidad de la cucaracha, pues el locutor se dirige a un alocutario representado singular.

\subsubsection{Inventio o la visión del mundo}

En el poema «Las cucarachas», el locutor personaje extiende una reflexión sobre una cucaracha multiplicada. La complejidad se revela cuando indica que mata a la señora cucaracha diariamente. ¿Cómo es posible esto? Por la multiplicación de los insectos. Para el locutor, todas las cucarachas son las mismas, son series que se propagan día tras día. Interesante alusión al sistema de reproducción en serie. De ese modo, se puede dirigir a la misma cucaracha todos los días y reflexionar como si fuera una sola. 
https://doi.org/10.46744/bapl.202101.004

La sinceridad inicial de los versos es contundente: «no la amo ni un poquito». Esto permite sostener la indiferencia de este animal en la vida del locutor, pero que insiste para mortificarlo, para convertirlo en asesino, si cabe el término en este caso. Esto debido a que la cucaracha invade el espacio privado. A pesar de la frugalidad de la aparición del insecto, el locutor lo siente como una invasión, como un atentado a lo que constituye su intimidad, sobre todo por lo que acarrea, los rastros desagradables de la muerte. Líquidos, pieles y patas quedan como huellas de una insistencia que perturba la vida íntima de quien reflexiona en el poema, de ahí que se dirige directamente al animal. Su reflexión se torna inmediata en la muerte, pues su reacción es instintiva: no ha tenido una formación sobre el arte de eliminar cucarachas; si se da, es gracias a una reacción que se activa por sentirse invadido.

Esta presencia sofocante se condice con el campo figurativo de la repetición en la anáfora y el asíndeton presentes en el poema. Como habíamos advertido, la anáfora creada por la repetición de la preposición sobre dibuja una relación asimétrica y jerárquica entre el locutor y su alocutario, y más sobre el cuerpo de este último. Por ello, se esquematiza la posición axiológica del locutor: su posición está por encima del insecto. También, más adelante, se presentan las reiteraciones a la propiedad, el cuarto y sus objetos, por medio del posesivo mi, y el cuerpo del insecto, por medio del posesivo su. Estas crean la sensación de sofocación por la presencia perturbadora del animal. El poema se conecta a nivel de forma y de contenido.

En «Las cucarachas», como en «Las moscas», se torna una interrupción en el espacio cotidiano del fastidio y el tedio de lo repetitivo, lo insistente de estos insectos, que — desde la perspectiva de este trabajometaforizan al sistema capitalista, el cual, como bichos, se agrega a los rincones de la vida, sofocando la presencia humana, alterando su orden, su vida privada, su desarrollo continuo. La incomprensión entre ambas dimensiones es capital: «Yo quisiera prevenirla» (v. 40). Este deseo muestra la falta comunicativa. Tal vez es la cucaracha que no entiende, que no comprende realmente su presencia indeseable. Así, el sistema capitalista se asocia a lo que se inmiscuye de manera sofocante en la vida del locutor. 
Esto se trasluce, además, en el deseo de acabarlo, de terminarlo para que la perspectiva de sosiego pueda actualizarse. Mientras las cucarachascapitalismo existan, solo queda la angustia de vivir viendo esos insectos sumamente molestos.

\subsection{Análisis de «Ellos», de Javier Heraud}

La alusión es notable en este poema: el «ellos» genera, por inversión, un «nosotros». Todo se juega en esta oposición. En este caso se está frente a un poema directo, de denuncia, de combate. La única forma de remediar al «nosotros» es eliminando al «ellos», pero para eso hay que señalarlos. Del mismo modo, se procederá a la identificación de las figuras retóricas para luego engarzarlas a la significación del poema y así identificar la cosmovisión.

\section{Ellos}

¿Dónde quedarán los traidores

a sueldo, los vendidos, los pobre diablos?

¿A dónde irá la bazofia del país, ellos que hablaron de «libertad», de «justicia, de «igualdad», cuando miles morían en los campos, (comuneros, campesinos, indios desarmados) bajo la balas del petróleo, de los latifundios, de los explotadores?

Dejemos nomás que escuchen los primeros tiros.

Dejemos nomás que vean al

primer campesino armado.

Dirán «es fácil». Y mandarán sus oficiales de plomo y de huiski.

Morirán estos. Mandarán otros.

$\mathrm{Y}$ casi, casi al final 
https://doi.org/10.46744/bapl.202101.004

se irán arrojando abajo

de las camas.

Se irán a las embajadas.

No importa. Los sacaremos de

sus inmundos huecos,

a todos juntos los juzgará

el pueblo.

Nadie podrá pedir clemencia para

ellos,

pues están solos.

Morirán ante el tribunal

del pueblo.

Nadie los llorará.

Pronto serán olvidados.

La Paz, 1963

\subsubsection{Dispositio o segmentación del poema}

El texto lírico «Ellos» consta de 33 versos, los cuales están divididos en cuatro segmentos. En el nivel de la dispositio, la segmentación del poema toma en cuenta las partes orationis del discurso retórico; esto es: exordio, narratio, argumentatio y peroratio. Vale decir que, al considerar el poema como discurso retórico, se inscribe la figura del alocutario; es decir, el lector implícito. En el segmento correspondiente a la exordio (la voz lírica se cuestiona acerca de adónde huirán los traidores de la patria), se presenta la causa del discurso, entre el verso 1 y 11 . En la narratio (la voz lírica narra cómo los traidores de la patria subestiman a los subordinados), se presentan los hechos que el discurso trata, va desde el verso 12 al 21. En la argumentatio (la voz lírica señala que los miembros del sistema capitalista huyeron hacia las embajadas), se mencionan las pruebas para la defensa de la causa, va del verso 22 al 26. Por último, en la peroratio (la voz lírica indica que los traidores de la patria serán juzgados y olvidados por el pueblo), se da la síntesis de lo anterior y la captación de la benevolencia del público, entre el verso 27 y 31 . 


\subsubsection{Elocutio o los campos figurativos}

En el poema «Ellos», predominan los campos figurativos de la metáfora y la metonimia. En el primer segmento, se evidencia el segundo campo mencionado: la contigüidad entre «traidores», «vendidos», «pobres diablos» alude a un conjunto único que se caracteriza por constituir una parte negativa del país. Y en los versos 4-11 — « ¿A dónde irá la bazofia del país, / ellos que hablaron de «libertad», / de «justicia», de «igualdad», / cuando miles morían en los campos, / (comuneros, campesinos, indios / desarmados) bajo las balas / de petróleo, de los latifundios, / de los explotadores?»—, a través del campo figurativo de la metáfora, la voz lírica expresa una denuncia en contra del sistema capitalista. La metáfora se refiere a que los miembros del capitalismo mataron a los subordinados «(comuneros, campesinos e indios desarmados)» cuando los explotaron en los latifundios y cuando les dispararon en el campo de batalla. Precisamente, los paréntesis encierran en sentido figurado a los que son presos de los desórdenes capitalistas. Así también, en estos versos se evidencia el campo figurativo de la metonimia, se señala que los dueños del petróleo (miembros del sistema capitalista) son quienes mataron a los subordinados. En el segundo segmento, en específico, en los versos 16-17 — «Dirán es fácil. Y mandarán / sus oficiales de plomo y de huiski»—, se presenta el mismo campo figurativo; esto es, relación de agente-acción que realiza el agente; se infiere que los oficiales que mataron a los subordinados son representantes del sistema capitalista, pues consumen bebidas alcohólicas burguesas como el «huiski». En el tercer segmento, en las líneas melódicas (v. 19-24) — «Y casi, casi al final / se irán arrojando debajo / de las camas. / Se irán a las embajadas. / No importa. Los sacaremos de / sus inmundos huecos»— se evidencia nuevamente el campo figurativo de la metáfora, en la que se indica que los representantes del sistema capitalista huyeron de la justicia hacia las embajadas. Finalmente, en el cuarto segmento, en los versos «Nadie podrá pedir clemencia para / ellos, / pues están solos. / Morirán ante el tribunal / del pueblo. / Nadie los llorará. / Pronto serán olvidados» (v. 27-33) se señala explícitamente, y sin la utilización de campos figurativos, que los representantes del sistema capitalista, los traidores de la patria, serán juzgados por la justicia del pueblo y que, además, serán olvidados fácilmente, ya que no realizaron ninguna hazaña beneficiosa que sea digna 
https://doi.org/10.46744/bapl.202101.004

de ser recordada. Mediante estas reflexiones, el locutor personificado en el poema denuncia los actos corruptos de los representantes del sistema capitalista; así como da cuenta de que dichos representantes del sistema serán hallados y juzgados por el pueblo.

\subsubsection{Interlectio o los interlocutores}

En el poema «Ellos», el locutor es personaje y el alocutario es no representado. A diferencia de los poemas anteriores, en este se formula una voz colectiva. Esto permite generar una confrontación de grupos a través de los interlocutores. Así, la oposición ocurre entre el «ellos» y el «nosotros». El locutor es una voz colectiva que remarca la naturaleza masiva del movimiento que se opone a los abusos de parte del sistema capitalista. Así, una presencia colectiva es enfrentada por otra del mismo calibre. Los verbos en primera persona del plural remarcan esta condición. Entonces, la relación entre interlocutores es tensiva, conflictiva.

\subsubsection{Inventio o la visión del mundo}

En el poema «Ellos», el locutor personificado colectivamente expresa una denuncia en contra de los miembros del sistema capitalista, quienes engañaron al pueblo con falsas promesas y, además, mataron a los subordinados mediante el trabajo explotador en las haciendas y a través de armas de fuego en el campo de batalla. Las dos interrogantes que abren la primera sección orientan sus lugares que ocuparán, luego de lo que se les aproxima: la justicia popular. Además, permiten confrontarlos con una realidad que no habían pensado hasta el momento por la comodidad que les había tocado vivir. Así, el locutor colectivo esgrime preguntas que son silenciadas en el instante continuo, pues no se abre un diálogo. Lo que viene a continuación es la invocación estratégica: «Dejemos nomás que escuchen / los primeros tiros» (v. 13-14).

El locutor propone, asimismo, el valor de la justicia, que solo será lograda cuando la organización de la sociedad se configure en una propuesta de índole socialista. Así, los subordinados o representantes del pueblo deberán tomar las armas y luchar en el campo de batalla con el fin de 
juzgar a los traidores de la patria, quienes serán olvidados fácilmente, ya que en su gobierno no realizaron ninguna hazaña en favor del pueblo digna de ser recordada. La táctica empleada por el locutor es la confianza que tienen «ellos». Su vanidad será su ruina: «Dirán «es fácil». Y mandarán / sus oficiales de plomo y huiski» (v. 17-18). Esta doble condición alude al control bajo la rigidez de las armas y el vicio de la bebida. Un control sobre los cuerpos absorbidos al sistema, cuerpos que son controlados mediante estrategias coercitivas y que cumplen la función de ordenadores. Pero esto está próximo a acabar.

En suma, en el poema se evidencia que la voz lírica no utilizó una gran profusión de campos figurativos para expresar su cosmovisión, pero sí utilizó las partes orationis del discurso retórico con el fin de convencer al lector de su tesis; esto es, la perspectiva política socialista infundirá justicia en el pueblo. Así, se concluye que, en el poema «Ellos», la voz poética no hizo uso del símbolo bisémico, el cual implica mayor complejidad en el esclarecimiento del sentido de los campos figurativos, porque su convicción política socialista señala que los discursos poéticos de los intelectuales revolucionarios deben ser claros, esto con el fin de ser comprendidos por todos. Esto se refuerza, como ya se advirtió, en el título, el pronombre solo señala a un grupo, los enemigos, los responsables de las injusticias, a quienes se deberá combatir si se quiere alcanzar el ideal de justicia popular al que aspira el locutor colectivo.

\subsubsection{Análisis comparativo de «Las cucarachas» frente a «Ellos»}

Al igual que lo expresado en la comparación anterior, se observa en la relación entre ambos poemas la función de los campos figurativos, aunque más acuciosamente en «Las cucarachas». La metáfora y la repetición son dos condiciones necesarias para construir el sentido del poema. La simbolización del capitalismo en dichos insectos y su insistencia en la vida del locutor hacen que este ejerza violencia con tal de verse librado del asedio diario de los bichos. En cambio, en «Ellos» se puede observar la preponderancia de los campos de la metonimia y de la metáfora. Los desplazamientos semánticos entre los actores y el sistema que representan intentan crear una continuidad entre causa y efecto de los males de la sociedad, para así, 
https://doi.org/10.46744/bapl.202101.004

metafóricamente, resolver las tensiones en favor de un «nosotros» que invoca a la justicia popular.

Los locutores de ambos poemas difieren radicalmente. La intimidad del primer poema se basa en una autorrepresentación del locutor, que se dirige hacia un alocutario representado para increparle su presencia molesta, incorregible e incontenible, que asedia constantemente su vida cotidiana, y que vuelve rutina asfixiante la vida con su presencia. Por otra parte, en «Ellos», la intención de contraponerle al título un «nosotros» permite leerlo en el sentido de inclusión. La fórmula del discurso retórico se centra en el convencimiento de vincular a más personas a su ideología política socialista, pues este no es un nosotros exclusivo, sino inclusivo; cualquiera que sienta desprecio por «los traidores / a sueldo, / los vendidos, / los pobres diablos» (v. 1-3) puede unirse en una causa común: sentencia poética, pero directa.

Del mismo modo, en el primer poema, el tono es coloquial y simbólico. La cucaracha tiene distintos planos de significación, tanto en su representación cotidiana como en su figuración de víctima necesaria. Esto crea una tensión entre la forma dialógica, coloquial, y el contenido profundo y reflexivo. En cambio, en el siguiente poema, se nota la rección del lenguaje. No hay solemnidad, sino movilización. El lenguaje es coloquial, pero serio. No hay espacio para la ironía, al menos no de modo gravitante. Si se puede ironizar, es internamente. Lo esencial es transmitir el lenguaje recto y seco para que no se confunda con una simple convocatoria, sino con la solución real de un cambio en las consciencias de los nuevos allegados al grupo. El lenguaje, por ello, se vuelve importante, con expresiones coloquiales se puede construir un discurso solemne, que esté a la altura del momento revolucionario.

\section{Conclusiones}

La poesía de Javier Heraud permite entender distintos modos de enunciación. Sus cambios formales o cambios de registros se entienden como una búsqueda de la mejor manera de expresar ciertas ideas o conceptos. Los tonos solemnes o coloquiales apuntan a distinguir las formas de construir el mensaje poético. 
Los textos poéticos de Heraud tienden hacia una rección del lenguaje, en la medida en que presentan carácter simbólico, en cierta forma, para trazar una poesía de corte inteligible. Su búsqueda va en función del contexto sociohistórico que le tocó vivir: los conflictos sociales en América Latina bajo el amparo del proyecto socialista de la Revolución cubana.

Las relaciones textuales son complejas en Heraud. Esto se evidencia en los poemas «Las moscas» $\mathrm{y}$ «Las cucarachas». Los títulos, las expresiones coloquiales y el sentido dialógico deberían apuntar a una poesía clarificada en cuanto al mensaje. Sin embargo, esto choca con el profundo simbolismo que emerge de los planos que se superponen en ambos poemas. Así, los insectos son perturbaciones cotidianas, pero también son el sistema capitalista, y así podría seguirse una cadena simbólica por la misma estructuración del poema.

Los poemas del conjunto «Poemas de Rodrigo Machado», por el contrario, a pesar de los tonos solemnes, serios, profundos conforman un corpus más claro en cuanto al mensaje, que —obviamente- no desmerecen su valor literario, sino que lo profundizan. Puesto que, aunque se comprenda de manera más nítida las intenciones de los poemas, estos no se reducen a meros textos panfletarios, sino a reflexiones en torno a los roles de las luchas revolucionarias y de sus múltiples actores. 
https://doi.org/10.46744/bapl.202101.004

\section{REFERENCIAS BIBLIOGRÁFICAS}

Albaladejo, T. (1991). Retórica. Síntesis.

Arduini, S. (2000). Prolegómenos a una teoría general de las figuras. Universidad de Murcia.

Chueca, L. (2020). (Nuestros) rostros de Javier. Apuntes sobre el poeta y su poesía. En K. Hanza, y L. F. Chueca, «Retorno con la dicha en la garganta». Javier Heraud: archivo y bibliografía (pp. 23-32). Departamento de Humanidades, PUCP.

Corcuera, J. (Director). (2019). El viaje de Javier Heraud [Documental]. Quechua Films Perú, La Mula Producciones y Tamboura Films.

Cornejo, J. (1966). Notas sobre la poesía de Javier Heraud. Javier Heraud/ Poesías completas, 1(3), 340-347. Campodónico ediciones.

Guillot, E. (Director). (2019). La pasión de Javier [Película]. Fondo Ibermedia de España y Ministerio de Cultura del Perú.

Guzmán-Zamora, F. (2009). La vida y la muerte en El río y El viaje de Javier Heraud. Naufragios, 1(1). https://bit.ly/2U0N3sr

Heraud, J. (1975). Javier Heraud/Poesías completas. Campodónico ediciones.

Perelman, CH. (1997). El imperio retórico. Retórica y argumentación (A. L. Gómez Giraldo, trad.). Norma. (Obra original publicada en 1977)

Steiner, G. (2001). Pasión intacta, Ensayos 1978-1995 (M. Gutiérrez y E. Castejón, trads., pp. 141-145). Siruela. (Obra original publicada en 1994) 
https://doi.org/10.46744/bapl.202101.004

Terol, M. (2017). Hacia un replanteamiento de la poesía social: el caso de Blas de Otero [Tesis Doctoral, Universidad de Sevilla]. Depósito de Investigación Universidad de Sevilla. https://idus.us.es/ bitstream/handle/11441/61167/tesis_maria_dolores_terol_ blas-otero.pdf? sequence $=1$ \&isAllowed $=\mathrm{y}$

Vargas Llosa, M. (1 de setiembre de 1961). La entrevista de Mario Vargas Llosa a Javier Heraud. Radiodifussion-Télévision Française, en Verboser.

Villacorta, C. (2014). Rodrigo Machado o la construcción del revolucionario Javier Heraud. Revista de Crítica Literaria Latinoamericana, 40(80), 251-264. 